\title{
Instructor-learner neural synchronization during elaborated feedback predicts
}

Yi Zhu ${ }^{1,2}$, Victoria Leong ${ }^{3,4}$, Yingying Hou ${ }^{1,2}$, Dingning Zhang ${ }^{1,2}$, Yafeng Pan ${ }^{1,5,6^{*}}$ and

1. School of Psychology and Cognitive Science, East China Normal University, Shanghai, China

2. Shanghai Key Laboratory of Mental Health and Crisis Intervention, East China Normal University, Shanghai, China

3. Division of Psychology, Nanyang Technological University, Singapore, Republic of Singapore

4. Department of Psychology, University of Cambridge, Cambridge CB2 3EB, United Kingdom

5. Department of Clinical Neuroscience, Karolinska Institutet, Stockholm, Sweden

6. Neuropsychology and Functional Neuroimaging Research Unit, ULB Neuroscience

\section{Author Note}

Data collection and preliminary analysis were sponsored by the National Natural Science Foundation of China (31872783 and 71942001). We have no conflicts of interest to disclose.

Correspondence concerning this article should be addressed to Yi Hu or Yafeng Pan. Yi $\mathrm{Hu}$, School of Psychology and Cognitive Science, East China Normal University, Shanghai, China, Email: yhu@psy.ecnu.edu.cn; Yafeng Pan, Department of Clinical Neuroscience, Karolinska Institutet, Stockholm, Sweden, Email: 
Abstract

The provision of feedback with complex information beyond the correct answer, i.e., elaborated feedback, can powerfully shape learning outcomes such as transfer, i.e., the ability to extend what has been learned in one context to new contexts. However, an understanding of neurocognitive processes of elaborated feedback during instructorlearner interactions remains elusive. Here, a two-person interactive design is used during simultaneous recording of functional near-infrared spectroscopy (fNIRS) signals from adult instructor-learner dyads. Instructors either provided elaborated feedback (i.e., correct answer and an example) or simple feedback (i.e., correct answer only) to learners during a concept learning task. Our results showed that elaborated feedback produced comparable levels of retention to simple feedback, however, transfer was significantly enhanced by elaboration. We also noted significant instructor-learner neural synchronization in frontoparietal regions during the provision of elaborated feedback, especially when examples were provided. Further, interpersonal neural synchronization in the parietal cortex successfully predicted transfer of knowledge to novel contexts. This prediction was retained for both learner-delayed and learnerpreceding neural synchronization. These findings point toward transfer effects of elaborated feedback provided in a social context can be predictable through interpersonal neural synchronization, which may hold important implications for realworld learning and pedagogical efficacy.

Keywords: elaborated feedback, transfer, instruction and learning, interpersonal neural synchronization, fNIRS hyperscanning 
bioRxiv preprint doi: https://doi.org/10.1101/2021.02 28.433286; this version posted June 19, 2021. The copyright holder for this preprint

(which was not certified by peer review) is the author/funder, who has granted bioRxiv a license to display the preprint in perpetuity. It is made available under aCC-BY-NC-ND 4.0 International license.

\section{Educational Impact and Implications Statement}

54 Feedback provides learners with crucial information regarding the gap between what

55 has currently been achieved and what remains to be achieved, and thus plays a critical

56 role in any learning process. In real-world settings, feedback is typically provided and

57 received through social interaction, and high-quality "elaborated feedback" contains

58 complex information that goes beyond the correct answer. This study aims to elucidate

59 the neurocognitive processes underpinning elaborated feedback during instructor-

60 learner interactions. We detected significant instructor-learner neural synchronization

61 in mutual frontoparietal brain regions during elaborated feedback, particularly during

62 the provision of specific elaborated information (i.e., concrete examples). Moreover,

63 this synchronization (including learner-delayed and learner-preceded synchronization)

64 in the parietal region predicted whether the learners transferred learning to novel

65 examples of learned psychology concepts. This study advances current understanding

66 on the neural mechanisms for elaborated feedback and the role of social interaction in

67 feedback effects. These results may have important implications for successful real-

68 world learning and communication, and related pedagogical applications in educational 69 settings. 


\section{Instructor-learner neural synchronization during elaborated}

\section{feedback predicts learning transfer}

\section{Introduction}

\section{Learning through social interaction. As we navigate the world, knowledge and} skills are often learned on the basis of communication with others during social interaction. The recent decade has witnessed a paradigm shift toward the concurrent measurement of multiple individuals engaging in social interaction (Dai et al., 2018; Kingsbury \& Hong, 2020; Redcay and Schilbach, 2019; Schilbach et al., 2013; Wheatley et al., 2019), including infant-adult dyads (Leong et al, 2017; Piazza et al., 2020; Santamaria et al, 2020; Wass et al, 2020) and individuals with neuropsychiatric disorders (Bilek et al, 2017; Leong \& Schilbach, 2019). Relevant research has indicated that interpersonal neural synchronization (INS) might underlie social interaction and underpin successful communication (for reviews, see Hasson et al., 2012; Redcay \& Schilbach, 2019). For example, Stephens et al. (2010) demonstrated that when communication was successful, the information provider's brain activity was spatiotemporally coupled with the information receiver's; INS also showed provideror receiver-preceding patterns, indicating the provider's dominance and the receiver's prediction, respectively.

Elaborated feedback as a powerful driver in learning. In communication and learning, feedback is a powerful driver of behavioural change as it provides the information regarding the gap between what is achieved and what is aimed to be achieved (Hattie \& Timperly, 2007; Mory, 2004). Prior research has identified feedback as a significant factor in student achievement, and learning motivation (e.g., Lepper \& Chabay, 1985; Narciss \& Huth, 2004). Although it is of great significance, feedback has been regarded as one of the least understood features in the instructional design (Cohen, 
1985; Gagne, 1970). In real-world settings, feedback is oftentimes provided and received during two-person interactions, and contains complex information beyond correct answer such as illustrative examples (Hattie \& Timperly, 2007). Any type of feedback supplying more complex information than correct answer is generally considered as elaborated feedback (Kulhavy \& Stock, 1989). Elaborated feedback has been found to deepen the understanding and promote the transfer to novel contexts (Bangert-Drowns et al., 1991; Butler et al., 2013; Finn et al., 2018; Kulhavy \& Stock, 1989, Bransford et al., 1999). However, a scientific understanding of the how elaborated feedback takes effects on learning during social interaction, remains largely elusive.

Single brain correlates of feedback. Using single-subject experimental designs, a number of studies have established that frontoparietal brain regions including the anterior cingulate cortex (ACC), the dorsolateral prefrontal cortex (DLPFC), and parietal lobules were implicated in the process of feedback messages such as yes-no verification and correct answer, which is regarded as simple feedback (Cavanagh et al., 2011; Crone et al., 2008; Mars et al., 2005; van Duijvenvoorde et al., 2008; Zanolie et al., 2008). Specifically, the ACC was responsible for basic functions such as error detection and expectation violation (Cavanagh et al., 2011; Luft et al., 2013; Mars et al., 2005), while the DLPFC and the superior parietal lobule was engaged in more complex processes such as error correction and performance adjustment (Crone et al., 2008; van Duijvenvoorde et al., 2008; Zanolie et al., 2008). Brain activation in these regions was related to feedback-based learning outcomes such as the memorization of pairedassociates (Arbel et al., 2013), response inhibition (McCormick and Telzer, 2018) and performance on reading and mathematics (Peters et al., 2017). To understand more about neurocognitive processes of elaborated feedback during social interaction, the simultaneous investigation of brain signals from interactive dyads is essential but 
lacking.

The role of INS in elaborated feedback effects. Within the general domain of social interaction and communication, INS has been found to hold specific implications of effective learning and instruction (Bevilacqua et al., 2018; Dikker et al., 2017; Holper et al., 2013; Meshulam et al., 2021; Nguyen et al., 2020; Pan et al., 2018; 2020; Piazza et al., 2021; Zheng et al., 2018). Based on the simultaneous recording of functional near-infrared spectroscopy (fNIRS) signals from multiple individuals during learning and instruction without the strict restraint of movement (Boas et al., 2014; Pinti et al., 2018), research has identified INS associated with learning outcomes. For instance, INS in the frontal cortex during educational interactions served as a correlate of learners' performance on singing (Pan et al., 2018) and on statistics (Liu et al., 2019). Besides, instructor-preceding neural synchronization in temporoparietal areas predicted the learners' performance on numerical reasoning (Zheng et al., 2018). Once feedback is combined with more complex information beyond the correctness, it becomes intertwined with instruction (Hattie \& Timperley, 2007). Thence, synchronized brain activity in instructor-learner dyads may offer a new lens into how elaborated feedback takes effects on learning in naturalistic educational settings.

The present study. Here, we applied fNIRS to simultaneously record brain signals from adult instructors and learners during an ecologically valid yet experimentally controlled educational interaction. Learners studied psychology concepts and received elaborated feedback or simple feedback from instructors. Elaborated feedback contained the correct answer and an example, illustrating the concepts in concrete and real-world situations, while simple feedback only contained the correct answer. Postlearning, learners were assessed for whether they recognized the definitions of learned psychology concepts (i.e., retention measure) and whether they transferred learning to 
bioRxiv preprint doi: https://doi.org/10.1101/2021.02 28.433286; this version posted June 19,2021 . The copyright holder for this preprint (which was not certified by peer review) is the author/funder, who has granted bioRxiv a license to display the preprint in perpetuity. It is made available under aCC-BY-NC-ND 4.0 International license.

identify novel examples of learned psychology concepts (i.e., transfer measure). We hypothesized that elaborated feedback enhanced learning performance, especially on

148 the transfer measure, relative to simple feedback. Providing and receiving elaborated

149 feedback would synchronize instructor-learner dyads' brain activity, potentially in 150 frontoparietal regions. Adults rely on the parietal cortex to process the informative and 151 efficient feedback for performance adjustment or error correction (Crone et al., 2008; van Duijvenvoorde et al., 2008). Elaborated feedback, regarded as informative and parietal instructor-learner neural synchronization would predict learning performance, especially transfer effects.

\section{Methods}

\section{Ethics statement}

This study was carried out according to the guidelines in the Declaration of Helsinki.

The study procedure was approved by Human Research Protection Committee at our

Participants were financially compensated for their participation.

\section{Participants}

Twenty-four healthy, female, right-handed participants were recruited as instructors.

165 They were required to major in psychology and complete at least one of teacher education courses. Besides, forty-eight healthy, female, right-handed participants were 
were randomly assigned into the elaborated feedback group (age $M=21.75, S D=2.42$ ),

while the other twelve into the simple feedback group (age $M=21.25, S D=2.93, t_{(22)}$

$=0.46, p=0.65)$. Each instructor was randomly paired with up to two learners. The

171 instructor taught each of the two learners using the same type of feedback (either

172 elaborated or simple feedback) individually over two adjacent days, resulting in a

173 between-subject design for both leaners and instructors. We chose this design to blind

elaborated feedback group $(M=19.63, S D=1.95)$ and simple feedback group $(M=$

$\left.19.79, S D=1.77, t_{(46)}=0.31, p=0.76\right)$. We merely recruited female dyads to control

179 for the potential impacts of gender difference (Baker et al., 2016; Cheng et al., 2015;

were naïve with respect to the purpose of the study.

\section{Materials}

Materials used for instruction and learning were about a set of ten psychology concepts

184 from the topic of judgement and decision making (Rawson et al., 2015). Each concept has a term, a one-sentence definition and two examples (view details in Table S1). as follows. 


\section{Experimental protocol}

The experiment was carried out over two visits to the laboratory, with the interval of one or two days (Figure 1a).

During visit 1 , learners completed a pre-learning test $(<15 \mathrm{~min})$ assessing their prior knowledge relative to those ten psychology concepts. Specifically, learners were required to match 10 definitions with 10 terms from provided 12 terms (c.f. Allen and Brooks, 1991; Finn et al., 2018; Murphy, 2004). The extra two terms were also from the same topic of judgement and decision making (view details in Table S1). The prior knowledge was quantified in forms of accuracy on pre-learning test (i.e., dividing the number of correctly matched concepts by the number of all concepts). As expected, learners had comparable prior knowledge in the elaborated vs. simple feedback group $\left(M \pm S D, 0.58 \pm 0.19\right.$ vs. $\left.0.58 \pm 0.26, t_{(46)}=0, p>0.999\right)$. Besides, learners completed a battery of scales with regard to learning and motivation: (i) Achievement Goal Orientation (Button et al., 1996); (ii) Academic Self-efficacy (Pintrich \& Groot, 1990); (iii) Learning Engagement (Schaufeli et al., 2002). No significant differences on scales for two feedback groups were detected ( $t \mathrm{~s}<1.60, p \mathrm{~s}>0.10$ ). During visit 1 , instructors underwent a standardized training on the instructional procedure and content $(\sim 30 \mathrm{~min})$. Afterwards, instructors brought home the print copies of the instruction materials and were required to learn and recite the concepts for their definitions and examples (see details in Table S1) at home. Upon coming back to the laboratory for visit 2, instructors were required to correctly recall the instructional procedure, together with the definitions and examples of two randomly selected concepts by the experimenter. Instructors were not allowed to carry out formal instruction until they met those requirements.

Visit 2 consisted of two sessions: fNIRS hyperscanning and post-hyperscanning. 
During the first session, instructors and learners sat face-to-face approximately 1 meter apart, wearing the fNIRS equipment. This session consisted of three phases: rest, introduction and feedback.

In the rest phase (300 s), both instructors and learners kept their eyes closed, motion restrained and mind relaxed. In the introduction phase, instructors introduced 10 concepts one by one with the term and definition orally presented twice. The introduction order of the concepts was self-decided by instructors in advance. In this phase, learners listened to the introduction with the permission of requesting the repetition of unclear parts. This phase was self-paced and instructor-learner dyads in elaborated vs. simple feedback group spent comparable time (337.77 $\mathrm{s} \pm 62.02$ vs. $\left.330.78 \mathrm{~s} \pm 66.86, t_{(46)}=0.38, p=0.71\right)$.

In the feedback phase, learners re-studied the 10 concepts based on the instructor's periods: question, answer, feedback and confidence. Specifically, instructors first presented a definition and questioned learners which term corresponded to the definition. Then, learners gave an answer. Next, instructors provided elaborated or simple feedback to learners depending on which feedback group she was assigned in. Simple feedback merely involved the correct answer, which consisted of the term and the definition, while elaborated feedback involved the correct answer and an additional example. Finally, learners judged the confidence that they would correctly answer the relevant questions in the post-hyperscanning session via number keyboards $(0-9$, very low to very high). One trial for elaborated feedback group was exemplified as follows. foreseen the outcome. Which term did this definition correspond to? 
has occurred, to overestimate one's ability to have foreseen the outcome. Here is an example.

248 but should be different from that in the introduction phase. As expected, instructor249 learner dyads in elaborated vs. simple feedback group spent longer time in the feedback period (339.54 $\mathrm{s} \pm 48.42$ vs. $\left.137.13 \mathrm{~s} \pm 28.38, t_{(46)}=17.67, p<0.001\right)$. To note, instructor-learner dyads in elaborated feedback group spent $136.04 \mathrm{~s} \pm 22.22$ and 203.50 $\mathrm{s} \pm 30.06$ for the correct answer and example part, respectively. The whole process of

the fNIRS hyperscanning session was also recorded via a digital video camera (Sony, showed no difference between the two feedback groups $(t=0.82, p=0.421)$. Next,

258 learners completed a post-learning test $(<15 \mathrm{~min})$ measured both the retention of 259 knowledge and the transfer of knowledge to novel contexts. On the retention measure, 260 learners were required to match 10 definitions with 10 terms from provided 12 terms, 261 which was identical with the pre-learning test. On the transfer measure, learners had to 262 match 10 novel examples with 10 terms from provided 12 terms (c.f. Finn et al., 2018). 263 To note, the selection of examples for use in elaborated feedback (i.e., Example 1 in 264 Table S1) vs. transfer measure (i.e., Example 2 in Table S1) was previously decided by 265 the experimenters without replacement. The elaboration example and the specific 266 context/topic provided for the transfer measure were not similar as assessed by an 267 additional group of raters $(N=20,16$ females, age $M=24.45, S D=2.89$; see 268 Supplementary Methods for details). 


\section{fNIRS data acquisition and preprocessing}

Instructors' and learners' brain activity was simultaneously recorded during the hyperscanning session of visit 2 using an ETG-7100 optical topography system (Hitachi Medical Corporation, Japan). Two optode probes were used for each participant: a $3 \times 5$ probe covering frontal areas (eight transmitters and seven detectors resulting in 22 measurement channels, i.e., $\mathrm{CH} 1-22)$ and a $4 \times 4$ probe covering left temporoparietal areas (eight transmitters and eight detectors resulting in 24 measurement channels, i.e., $\mathrm{CH} 23-46)$, see Figure $1 \mathrm{~b}$ for the reference and channel locations. The probes were placed over frontal and temporoparietal areas because these regions have been implicated in feedback-based learning (Crone et al., 2008; Luft, 2014; van Duijvenvoorde et al., 2008) as well as learning and instruction (Liu et al., 2019; Pan, et al., 2018; Zheng et al., 2018). Temporoparietal areas were focused on the left hemisphere rather than the right hemisphere due to the former is dominant for language functions (Ojemann et al., 1989; Vigneau et al., 2006), which is an essential component of concept learning. The correspondence between NIRS channels and measured points on the cerebral cortex was determined using the virtual registration approach (Singh et al., 2005; Tsuzuki et al., 2007; see details in Table S2).

The optical data were collected at the wavelengths of 695 and $830 \mathrm{~nm}$, with a sampling rate of $10 \mathrm{~Hz}$. The preprocessing of fNIRS data was performed using custom MATLAB (MathWorks, Natick, MA, USA) scripts and Homer2 toolbox (version 2.2, Huppert et al., 2009). The raw optical intensity data series were first converted into changes in optical density (OD). Channels with very low or high OD, which exceeded 5 SDs, were marked as unusable and removed from the analysis. Next, OD time series were screened and corrected for motion artifacts using a channel-by-channel waveletbased method. The Daubechies 5 (db5) wavelet was chosen (Molavi \& Dumont, 2012) 
and the tuning parameter was set to 0.1 (Cooper et al., 2012). A band-pass filter with cut-off frequencies of $0.01-1 \mathrm{~Hz}$ was applied to the OD data in order to reduce the slow drift and high frequency noise. The OD time data were then converted into oxyhemoglobin $(\mathrm{HbO})$ and Deoxyhemoglobin $(\mathrm{HbR})$ concentration changes based on

298 the modifier Beer-Lambert Law (Cope \& Delpy, 1988). In the current study, we mainly 299 focused on $\mathrm{HbO}$ concentration change, which was considered as an indicator of the change in regional cerebral blood flow with higher signal-to-noise ratio (Hoshi, 2007) and has been more widely used in fNIRS hyperscanning research (e.g., Cheng et al., 2015; Hu et al., 2017; Jiang et al., 2015; Pan et al., 2017; Dai et al., 2018; Yang et al., 303 2020).

\section{Data analysis}

\section{Behavioral data analysis}

Learning performance was assessed by post-learning test and quantified in forms of accuracy (i.e., dividing the number of correctly answered items by the number of all

308 items). Besides, learners' knowledge immediately before feedback (i.e., on the answer period of the feedback phase) was also quantified in forms of accuracy, which was comparable between simple feedback group $(M \pm S D, 0.67 \pm 0.21)$ and elaborated feedback group $\left(0.62 \pm 0.15, t_{(46)}=0.82, p=0.41\right)$.

First, we sought to verify whether conceptual knowledge was promoted by 313 elaborated feedback. Because each instructor was randomly assigned to teach two 314 learners, learners were nested within instructors. A linear mixed model (West et al., 315 2014) was thus fitted on learners' accuracy including fixed effects of test time (pre316 learning vs. post-learning), plus random effects on learner and instructor identity. 317 Accuracy on the answer period of the feedback phase and the duration of elaborated 
feedback were additionally entered in the model to control for their potential effects. plus random effects of learner and instructor identity. Accuracy on the pre-learning test, accuracy on the answer period of feedback phase and the duration of feedback were additionally entered in the model to control for their potential effects. Besides, a parallel model was fitted on learners' accuracy on the transfer measure.

Finally, an additional linear mixed model was conducted on confidence ratings including a fixed effect of feedback type (elaborated vs. simple), plus random effects of learner and instructor identity.

All behavioral analyses were computed using functions implemented in MATLAB

Restricted maximum likelihood was used to estimate the models. $F$ and $p$ values were derived using anova function based on Satterthwaite approximation.

fNIRS data analyses

WTC analysis. Interpersonal neural synchronization (INS) between instructors and

335 learners was computed by a wavelet transform coherence (WTC) algorithm, which estimates the correlation of a pair of time series as a function of frequency and time (Grinsted et al., 2004; Torrence \& Compo, 1998). First, preprocessed HbO time series

338 were extracted from homologous regions (following previous studies, e.g., Cui et al., 339 2012; Hu et al., 2018; Jiang et al., 2012; Liu et al., 2019; Pan et al., 2018; 2020). For 340 instance, two signals ( $i$ and $j$ ) could be respectively extracted from instructors' $\mathrm{CH} 45$ 341 and the learners' CH45 (Figure 1b). Then, WTC of signals was computed by following 
formula:

$$
\operatorname{WTC}(t, s)=\frac{\left|\left\langle s^{-1} W^{i j}(t, s)\right\rangle\right|^{2}}{\left|\left\langle s^{-1} W^{i}(t, s)\right\rangle\right|^{2}\left|\left\langle s^{-1} W^{j}(t, s)\right\rangle\right|^{2}}
$$

where $t$ denotes the time, $s$ indicates the wavelet scale, $\langle\cdot\rangle$ represents a smoothing operation in time and scale, and $W$ is the continuous wavelet transform. Then, a 2-D (time $\times$ frequency) WTC matrix was generated (Figure 1b, see more details in Chang \& Glover, 2010; Grinsted et al., 2004).

In this study, we specifically investigated INS associated with elaborated feedback (for general instruction and learning, see Liu et al., 2019; Pan et al., 2018; 2020; Zhang et al., 2018). To this end, time points corresponding to the start and the end of feedback (i.e., the feedback period, Figure $1 b$ ) were marked based on the recorded videos and was adjusted for the delay-to-peak effect by 6 s (Cui et al., 2009; Jiang et al., 2015). Accordingly, elaborated feedback could be further segmented into two parts (i.e., correct answer and example, Figure 1b).

Cluster-based permutation test. Interpersonal interactions as opposed to resting state elicited significantly larger INS (Cui et al., 2012; Jiang et al., 2012). For each dyad and each channel combination, WTC values during the feedback period and the rest phase (leaving out first and last minutes to retain more steady data) were respectively time-averaged, and then converted into Fisher $z$-values. Accordingly, we sought to identify frequency-channel clusters showing significantly larger WTC during elaborated feedback vs. rest using a cluster-based permutation test. It is a nonparametric statistical test that offers a solution to the problem of multiple comparisons for multi-channel and multi-frequency data (Maris \& Oostenveld, 2007). We conducted it following five steps. First, we ran frequency-by-frequency and channel-by-channel linear mixed models including a fixed effect of task (feedback vs. rest), plus random effects of learner and instructor identity. Considering the process of elaborated feedback 
was self-paced, duration was entered in the model to control for its potential effect.

Next was to identify channels (46 in total) and frequency bins (80 in total, ranging from

0.01 to $1 \mathrm{~Hz}$ ), at which the task effect was significant (feedback $>$ rest, $p<0.05$ ). To

note, we excluded 12 respiration-related frequency bins from 0.15 to $0.3 \mathrm{~Hz}$ and 7

cardiac-related frequency bins above $0.7 \mathrm{~Hz}$ (Nozawa et al., 2016; Zheng et al., 2018),

remaining 60 frequency bins (see in Supplementary material, Figure S1). Third was to

form clusters composed of neighboring channels $(\geq 2)$ and neighboring frequency bins

$374(\geq 2)$ and compute the statistic for each cluster by summing all $F$ values. Fourth, repeat normalize the distributions) with $p$ value assessed by following formula (Theiler et al., 
bioRxiv preprint doi: https://doi org/10.1101/2021.0228 433286; this version posted June 19 2021. The copyright holder for this preprint

(which was not certified by peer review) is the author/funder, who has granted bioRxiv a license to display the preprint in perpetuity. It is made available under aCC-BY-NC-ND 4.0 International license.

in the following analyses, which was computed by subtracting WTC (averaged by

channels and frequency bins contained in the cluster) during task from that during rest, and then converted into Fisher $z$-values. Before entering the contrast analysis, time series of $\triangle \mathrm{WTC}$ during elaborated feedback was segmented into two parts, i.e., correct answer and example, based on the recorded videos (Figure S3). Instructor-learner dyads in the elaborated feedback group spent $136.04 \mathrm{~s} \pm 22.22$ and $203.50 \mathrm{~s} \pm 30.06$ for the correct answer and example part, respectively $(t=15.58, p<0.001)$. Then the contrast

(Figure S3). First, compare $\Delta \mathrm{WTC}$ during correct answer and example contained in 401 elaborated feedback. Specifically, a linear mixed model was fit on $\Delta$ WTC associated with two parts of elaborated feedback, including a fixed effect of feedback information

Considering the varying data length across feedback information and across dyads, 405 duration of feedback information was entered in the model to control for its potential 406 effect. Second, compare $\triangle$ WTC during simple feedback (correct answer only) and the example part of elaborated feedback, using an identical linear mixed model as that in the first step. Multiple comparisons were corrected using the false discovery rate (FDR) method (Benjamini and Hochberg, 1995) to calculate corrected $p$ values.

\section{Behavior-brain relation analyses}

411 Next, we tested whether instructor-learner neural synchronization associated with 412 elaborated feedback predicted learning performance. To control for individual 413 differences, relative accuracy was used in the following analysis, which was computed 414 by subtracting z-score of accuracy on the pre-learning test from that on the post-learning 415 test. A machine learning algorithm, i.e., linear support vector regression (SVR), was 
applied to train $\triangle \mathrm{WTC}$ for each identified cluster for the prediction of relative accuracy.

417 To avoid the potential information loss by the trial-averaged $\Delta$ WTC value, we instead 418 extracted trial-by-trial $\Delta \mathrm{WTC}$ values, which was then used as up to ten features for the 419 training. We used a leave-one-out cross-validation approach via Regression Learner APP implemented in MATLAB (R2018a, MathWorks). The prediction analysis was performed by doing such a training first on all but one dyad and then testing on the leftout dyad to examining the generalization of prediction of relative accuracy based on trial-by-trial $\Delta$ WTC. The prediction analysis was performed $n$ times $(n=$ total number of dyads). Prediction accuracy was quantified by the Pearson correlation coefficient $(r)$ between the observed and predicted relative accuracy (Hou et al., 2020; Kosinski et al.,

428 feedback unfolded over time, when the aforementioned prediction analyses showed 429 significant results $(r>0$ and $p<0.05)$, we added various time shifts (instructor's brain activity was shifted forward or backward relative to the learner's by 1-14 s, step =1 s) Hochberg, 1995) calculating corrected $p$ values.

\section{Results}

\section{Elaborated feedback promoted the transfer of knowledge} higher than that on the pre-learning test $\left(0.58 \pm 0.19, F_{(1,23)}=58.50, p<0.001, \beta=0.25\right.$, $\mathrm{SE}=0.03,95 \%$ confidence interval $(\mathrm{CI})=0.19$ to 0.32$)$. It was indicated that elaborated

438 feedback promoted learners' conceptual knowledge. Next, we investigated whether 439 elaborated feedback relative to simple feedback promoted learning. On the retention 
measure, learners' accuracy was comparable in the elaborated feedback group $(0.96 \pm$

$4410.09)$ and simple feedback group $\left(0.94 \pm 0.14, F_{(1,21.17)}=1.90, p=0.183, \beta=0.04, \mathrm{SE}\right.$

$442=0.03,95 \% \mathrm{CI}=-0.02$ to 0.09$)$. However, on the transfer measure, a parallel model 443 analysis revealed that learners' accuracy in the elaborated feedback group $(0.70 \pm 0.21)$

444 was significantly higher than that in the simple feedback group $\left(0.59 \pm 0.21, F_{(1,15.63)}=\right.$ $4455.42, p=0.031, \beta=0.14, \mathrm{SE}=0.06,95 \% \mathrm{CI}=0.02$ to 0.26$)$. It was indicated that 446 elaborated feedback relative to simple feedback promoted transfer rather than retention 447 of knowledge. Besides, for the confidence rating, no significant effect was revealed $\left(F_{(1}\right.$, $448 \quad 22)=0.49, p>0.100)$.

Elaborated feedback synchronized instructor-learner dyads' neural activity in the

451 We investigated whether instructor-learner dyads providing and receiving elaborated feedback as opposed to resting elicited significantly larger WTC using a cluster-based permutation test. Two significant channel-frequency clusters were identified (Figure 2 and Table S3). Cluster 1 was composed of 2 spatially neighboring channels, i.e., CH42, $\mathrm{CH} 45$, in 8 frequency bins, ranging from 0.017 to $0.025 \mathrm{~Hz}$ (cluster statistic $=11.54, p$ $456<0.001)$. The channels contained in Cluster 1 were approximately located at the left 457 parietal cortex, including the postcentral gyrus (PoCG) and superior parietal gyrus 458 (SPG). Cluster 2 was composed of 3 spatially neighboring channels, i.e., CH05, CH06, $459 \mathrm{CH} 10$, in 7 frequency bins, ranging from 0.017 to $0.024 \mathrm{~Hz}$ (cluster statistic $=6.62, p$ $460=0.005)$. The channels contained in Cluster 2 were approximately located at the left 461 frontal cortex, including the superior frontal gyrus (SFG) and middle frontal gyrus 462 (MFG). In addition, instructor-learner synchronization on Cluster 1 and Cluster 2 463 exhibited temporal patterns, i.e., the learners' brain activity synchronized with 
instructors' with some delay or the opposite (see details in Supplementary Results, Figure S4).

Additionally, granger causality analysis was performed to explore the information flow during the period of elaborated feedback from instructor to learner or from learner to instructor on brain regions corresponding to the identified clusters (see more details

471 providing and receiving elaborated feedback (see more details in Supplementary

472 Results, Figure S2).

\section{Frontoparietal instructor-learner synchronization was specific to examples}

To further characterize the brain regions synchronized by different feedback information, brain activity during elaborated feedback was segmented into two parts

(i.e., example and correct answer) and respectively compared with that during resting

477 using a cluster-based permutation test. For the example part of elaborated feedback, two 478 significant channel-frequency clusters were identified (Figure 3 and Table S4). Cluster 4793 was composed of 2 spatially neighboring channels, i.e., $\mathrm{CH} 42, \mathrm{CH} 45$, in 8 frequency bins, ranging from 0.018 to $0.027 \mathrm{~Hz}$ (cluster statistic $=13.69, p<0.001$ ). The channels contained in Cluster 3 were approximately located at the left parietal cortex, including

482 the PoCG and SPG. Cluster 4 was composed of 3 spatially neighboring channels, i.e., $483 \mathrm{CH} 05, \mathrm{CH} 06, \mathrm{CH} 10$, in 8 frequency bins, ranging from 0.015 to $0.023 \mathrm{~Hz}$ (cluster 484 statistic $=10.61, p<0.001)$. The channels contained in Cluster 4 were approximately 485 located at the left frontal cortex, including the SFG and MFG. To note, Cluster 1 and 486 Cluster 3 contained identical channels, while Cluster 2 and Cluster 4 contained identical 487 channels. In addition, the synchronized brain activity on Cluster 3 and Cluster 4 
bioRxiv preprint doi: https://doi org/10.1101/2021.02 28.433286; this version posted June 19,2021 . The copyright holder for this preprint (which was not certified by peer review) is the author/funder, who has granted bioRxiv a license to display the preprint in perpetuity. It is made available under aCC-BY-NC-ND 4.0 International license.

exhibited temporal patterns, i.e., the learners' brain activity synchronized with instructors' with some delay or the opposite (see details in Supplementary Results, channel-frequency cluster was identified (Table S4). Simple feedback (only containing the information of correct answer) was also compared with rest using a cluster-based permutation test and no significant channel-frequency cluster was identified (Table S5). It was indicated that instructor-learner neural synchronization on frontoparietal regions was specific to the example rather than correct answer part of elaborated feedback.

Next, contrast analysis was conducted between different forms of feedback information (example vs. correct answer) by two steps, on Cluster 3 and Cluster 4, respectively. The first was to compare $\Delta$ WTC during the example and correct answer contained in elaborated feedback, and the second was to compare $\triangle \mathrm{WTC}$ during the 500 example part of elaborated feedback and simple feedback (correct answer only) based 501 on linear mixed models. On Cluster 3, providing and receiving the example vs. correct answer part of elaborated feedback elicited larger $\triangle$ WTC (feedback minus rest) $(0.10$ \pm 0.12 vs. $0.09 \pm 0.11, F_{(1,23.70)}=8.21, p=0.009$, corrected $p=0.018, \beta=0.15, \mathrm{SE}=$ 505 showing a significant effect $\left(F_{(1,27.87)}=11.486, p=0.002, \beta=-0.002, \mathrm{SE}=0.001,95 \%\right.$

$506 \mathrm{CI}=-0.003$ to -0.001$)$; providing and receiving the example part of elaborated feedback 507 vs. simple feedback also elicited larger $\Delta \mathrm{WTC}\left(0.10 \pm 0.12\right.$ vs. $0.01 \pm 0.14, F_{(1,26.60)}=$ $5084.75, p=0.037$, corrected $p=0.049, \beta=0.13, \mathrm{SE}=0.06,95 \% \mathrm{CI}=0.01$ to 0.24 , Figure $5094 a)$, with the duration of feedback information showing non-significant effect $\left(F_{(1,31.17)}\right.$ $510=0.56, p=0.461, \beta=-0.000, \mathrm{SE}=0.001,95 \% \mathrm{CI}=-0.002$ to 0.001$).$ On Cluster 4, 511 providing and receiving the example vs. the correct answer part of elaborated feedback 512 elicited comparable $\Delta \mathrm{WTC}\left(0.12 \pm 0.13\right.$ vs. $0.11 \pm 0.13, F_{(1,19.73)}=2.46, p=0.133$, 
corrected $p=0.133, \beta=0.09, \mathrm{SE}=0.06,95 \% \mathrm{CI}=-0.03$ to 0.22 , Figure $4 \mathrm{~b}$ ), with the

0.13 vs. $0.03 \pm 0.17, F_{(1,45)}=9.39, p=0.004$, corrected $p=0.016, \beta=0.20, \mathrm{SE}=0.06$,

$95 \% \mathrm{CI}=0.07$ to 0.32 , Figure $4 \mathrm{~b}$ ), with the duration of feedback information showing $-0.000)$

Parietal instructor-learner neural synchronization predicted the transfer of

Next, we tested whether instructor-learner neural synchronization during providing and receiving elaborated feedback could predict learning performance. A SVR was trained on $\triangle$ WTC associated with the example part of elaborated feedback on Cluster 3 and Cluster 4 to respectively predict learners' accuracy on the post-learning test relative to the pre-learning test. It was revealed in Figure 5a that trial-by-trial $\triangle$ WTC on Cluster 3 could successfully predict out-of-sample learners' relative accuracy on the transfer measure $\left(r=0.57, R^{2}=32.49 \%, p=0.004\right)$ but not on the retention measure $\left(r=0.25, R^{2}=6.25 \%, p=0.241\right)$; trial-by-trial $\Delta \mathrm{WTC}$ on Cluster 4 could not predict learning performance $\left(r \mathrm{~s}<-0.09, R^{2} \mathrm{~s}<0.81 \%, p \mathrm{~s}>0.05\right)$. A similar

532 prediction pattern was seen for synchronized neural activity associated with elaborated 533 feedback (see more details in Supplementary Results, Figure S6a). 
instructors' brain activity preceded learners' by 1-10 s and when learners' preceded the instructors' by $1-13 \mathrm{~s}$ (corrected $p \mathrm{~s}<0.05$, Figure $5 \mathrm{~b}$ ). With time shifts, the prediction accuracy on the retention measure remained insignificant (corrected $p \mathrm{~s}>0.05$, Figure $5 b)$. With time shifts, a similar prediction pattern was seen for synchronized brain 541 activity associated with elaborated feedback (see more details in Supplementary Results, 542 Figure. S6b).

\section{Discussion}

544 Our findings support the notion that providing learners with elaborated feedback 545 relative to simple feedback promotes the transfer of conceptual knowledge to novel 546 contexts. The neurocognitive processes of elaborated feedback during instructor-learner 547 interactions were investigated from an inter-brain perspective. When elaborated

548 feedback unfolded overtime, we found synchronized instructor-learner dyads' brain 549 activity in frontoparietal regions, including the superior frontal gyrus (SFG), middle 550 frontal gyrus (MFG), postcentral gyrus (PoCG) and superior parietal gyrus (SPG). Such 551 instructor-learner synchronization was specific to complex information, i.e., example, 552 contained in the elaborated feedback. Based on a machine learning algorithm, 553 instructor-learner synchronization associated with example in the parietal cortex 554 successfully predicted out-of-sample learners' ability to transfer knowledge to novel 555 contexts. Such a prediction was retained when instructors' brain activity preceded 556 learners' by 1-10 s and when learners' preceded instructors' by 1-13s. 
feedback, adding example or explanation to feedback promotes the learning of

feedback relative to correct answer feedback on learning have also been reported (e.g.,

Andre \& Thieman, 1998; Kulhavy et al., 1985; Mandernach, 2005). It may be due to

that the added information is too lengthy or complex to be processed and even offsets

568 found that providing learners with elaborated feedback containing example relative to

569 correct answer feedback resulted in comparable retention of knowledge. However,

570 when learners' ability to transfer conceptual knowledge to novel contexts was tested,

571 elaborated feedback tended to be of benefit. These findings supported the superior effect

572 of elaborated feedback on knowledge transfer rather than knowledge retention. To note,

573 in the current study, learning gains were measured almost immediately after the

574 hyperscanning session. Follow-up studies should have another post-test with a delay

575 interval (e.g., one week) to explore whether the effects of elaborated feedback are

576 retained over longer intervals.

577 Metacognitive effects of elaborated feedback are also recognized as a crucial

578 factor in feedback research. Correct answer feedback not only facilitates the correction

579 of erroneous responses with high confidence (Butterfield \& Metcalfe, 2001, 2006;

580 Pashler et al., 2005), but also calibrates metacognitive errors on low-confidence correct

581 responses (Butler et al., 2008; Thomas \& McDaniel, 2013). Feedback, especially

582 elaborated feedback, may improve the calibration and item-level accuracy of

583 metacognitive judgments. In particular, the processing of examples contained in

584 elaborated feedback might affirm or trigger re-evaluation of the learner's deeper

585 conceptual understanding. Moreover, elaborated feedback provided in a social context 
bioRxiv preprint doi: https://doi.org/10.1101/2021.02 28.433286: this version posted June 19, 2021. The copyright holder for this preprint (which was not certified by peer review) is the author/funder, who has granted bioRxiv a license to display the preprint in perpetuity. It is made available under aCC-BY-NC-ND 4.0 International license.

involves social cues and its efficacy would be expected to be moderated by social effects

such as relationship between the instructor and the learner. Besides, patterns of neural

synchronization might differ based on whether participant's answer in the feedback

this study restricted item-level analyses or conditional analyses on correct vs. incorrect

591 responses. Future research is required to explore whether feedback on correct vs.

is, learner-delayed or learner-preceded neural synchronization).

When instructor-learner dyads providing and receiving elaborated feedback, we

596 found synchronized brain activity in frontoparietal regions. Frontoparietal regions such as the anterior cingulate cortex (ACC), DLPFC and parietal lobules are well-localized

Crone et al., 2008; Luft et al., 2013; Mars et al., 2005; van Duijvenvoorde et al., 2008; Zanolie et al., 2008). Activity generated in the ACC, tracks a basic feedback function 601 of error detection and conflict monitoring (Cavanagh et al., 2011; Luft et al., 2013; Mars et al., 2005). Moreover, the DLPFC and parietal lobules play essential role in error correction and performance adjustment (Zanolie et al., 2008; van Duijvenvoorde et al., 2008). Besides, DLPFC is also implicated in social interaction (Kanske et al., 2015;

605 Schurz et al., 2014). In the current study, synchronized brain activity observed 606 approximately in the SFG, MFG, PoCG and SPL, which were spatially proximal to well-defined feedback sensitive regions, may underlie the providing and receiving 608 elaborated feedback by instructor-learner dyads in real-world educational settings. In 609 our study, we further demonstrated that instructor-learner synchronization in 610 frontoparietal regions was specifically associated with complex information, i.e., 
bioRxiv preprint doi: https://doi org/10.1101/2021.02.28 433286; this version posted June 19,2021 . The copyright holder for this preprint (which was not certified by peer review) is the author/funder, who has granted bioRxiv a license to display the preprint in perpetuity. It is made available under aCC-BY-NC-ND 4.0 International license.

example, contained in the elaborated feedback, whereas providing and receiving the correct answer failed to synchronize brain activity from instructors and learners. These results suggest that feedback information beyond the correct answer recruit separable

614 brain activity in instructor-learner dyads, which potentially supports the superior effect 615 of elaborated feedback on learning. with example in the parietal cortex rather than frontal regions successfully predicted out-of-sample learners' ability to transfer knowledge to novel contexts. In comparison with the ACC, parietal lobules mature late in feedback processing (Peters et al., 2016). Adults rely more on the parietal cortex than the ACC to process informative and 621 efficient feedback to adjust performance or correct errors (Crone et al., 2008; van Duijvenvoorde et al., 2008; Zanolie et al., 2008), which plays a more critical role in knowledge acquisition. Concrete examples contained in elaborated feedback tended to

624 be informative and efficient for concept learning and had advantages in facilitating 625 transfer (Bangert-Drowns et al., 1991; Butler et al., 2013; Finn et al., 2018; Kulhavy \& 626 Stock, 1989). The current study observed instructor-learner neural synchronization in 627 frontal regions but such neural synchronization had no connection to learning 628 performance. In line with previous research, feedback information tended to activate 629 frontal brain regions (Cavanagh et al., 2011; Mars et al., 2005). However, due to the 630 limited depth of NIR light penetration (Ferrari \& Quaresima, 2012), brain activity 631 generated as deep as from the "feedback-related" ACC (Cavanagh et al., 2011) might 632 not have been reliably tracked. Future studies could use fMRI hyperscanning to assess 633 the involvement of INS in frontal regions in feedback-based learning. In this study, 634 whether INS serves as a mechanism that supports learning or it is simply an 635 epiphenomenon also requires further careful and detailed examination (Hamilton, 2021; 
bioRxiv preprint doi: https://doi org/10.1101/2021.02.28 433286; this version posted June 19,2021 . The copyright holder for this preprint

(which was not certified by peer review) is the author/funder, who has granted bioRxiv a license to display the preprint in perpetuity. It is made available under aCC-BY-NC-ND 4.0 International license.

Wass et al., 2020; Novembre \& Iannetti, 2021; Pan et al., 2021a). One way to test the

causal role of INS in learning is using a multi-brain stimulation protocol (Novembre et

al., 2017; Novembre \& Iannetti, 2021; Pan et al., 2021b).

Interestingly, prediction effect of instructor-learner synchronization associated

640 with example in the parietal cortex retained when instructors' brain activity preceded

641 learners' by $1-10 \mathrm{~s}$ and when learners' preceded instructors' by $1-13 \mathrm{~s}$. The processing

642 of high-level linguistic structures such as sentences and paragraphs is at timescale of seconds, whereas that of sound-level acoustic features is milliseconds (Hasson et al., 2015). In average, each example was presented with 2.4 sentences, lasting for about 20.3 second. Therefore, the maximal temporal shifts are more likely to reflect sentence-

646 level rather than word- or syllable-level processing. Transfer tends to occur when the 647 prior learned knowledge is represented at deeper levels, e.g., abstract structure and 648 personal interpretation, instead of surface levels, e.g., specific words and syntax 649 (Graesser et al., 1997; Kintsch, 1998). To extract the abstract structure of knowledge 650 demands a sufficient amount of information being transmitted from instructors to 651 learners and the integration of such information over a time window (Stephens et al., 2010; Tatler et al., 2003). Accordingly, this predicts that learner-delayed neural 653 synchronization may predict transfer effects. If knowledge was represented into 654 personal interpretation, learners would be able to predict the upcoming information 655 before it was completely provided (DeVault et al., 2011; Pickering \& Garrod, 2013), 656 resulting in learner-preceding neural synchronization that predicts transfer effects. In 657 the current study, we found that instructor-learner neural synchronization with temporal 658 shifts (both learner-delayed and learner-preceded) could successfully predict transfer, 659 which provides preliminary supporting evidence to the notion that deeper-level 660 representations of knowledge in parietal regions may promote transfer. Nevertheless, 
661

662

663

664

\section{5}

666

667

668

669

679 the instructors' and learners' homologous regions across different time lags (i.e., one's

680 brain activity precedes that of the other). Considering the instructors and the learners

681 are expected to have different roles (i.e., teaching and learning), neural synchronization

682 between different brain regions or that with time lags is expected (Jiang et al., 2021;

683 Zheng et al., 2018; Liu et al., 2017). Due to the limited channels of fNIRS, our optode

684 probe set only covered the frontal cortex and left temporoparietal regions, leaving the

685 functions of other regions unexplored. Future studies are encouraged to consolidate our 
bioRxiv preprint doi: https://doi.org/10.1101/2021.02 28.433286; this version posted June 19, 2021. The copyright holder for this preprint

(which was not certified by peer review) is the author/funder, who has granted bioRxiv a license to display the preprint in perpetuity. It is made available under aCC-BY-NC-ND 4.0 International license.

686

687

688

689

690

691

692

693

694

695

696

697

698

699

700

701

702

703

704

705

706

707

708

709

710

findings by using whole-brain coverage and by further exploring the neural synchronization between different regions in instructors and learners. Third, frequencies of instructor-learner neural synchronization associated with elaborated feedback were roughly identified within 0.01 to $0.03 \mathrm{~Hz}$, overlapping some of those identified by previous fNIRS hyperscanning studies using communication paradigms (e.g., Jiang et al., 2012; 2015) and education tasks (e.g., Zheng et al., 2018). Future research may wish to further characterize INS for its potential significance in the frequency domain as EEG signals in terms of ranges and functions (Henry, 2006; Teplan, 2002). Fourth, considering that feedback effects could be mediated by learners' prior knowledge (Fyfe et al., 2012; Krause et al., 2009) and metacognitive judgment (Butler et al., 2008; Thomas \& McDaniel, 2013), future work is expected to be more prudent when screening learners. For example, apart from not being Psychology majors, learners are also expected to not have taken a Psychology class in recent years. Their degree of confidence or certainty in the correctness of the testing items should also be assessed. Besides, only female dyads were tested in order to reduce the sample variability, in accordance with previous evidence and recommendations (Baker et al., 2016; Cheng et al., 2015; Tang et al., 2019). Future studies should consolidate and generalize the current findings to male participants. Last but not the least, the critical role of social factors, such as communication mode (e.g., human-human, humancomputer) and relationship between instructors and learners (e.g., trust, rapport), in shaping learning from feedback might be a fruitful direction for future investigations.

In summary, the current results suggest that the feedback information beyond the correct answer could promote learning, especially for transfer of knowledge to novel contexts. Extending previous findings based on computer-controlled paradigms, this study used an ecologically valid yet experimentally controlled feedback-based concept 
bioRxiv preprint doi: https://doi org/10.1101/2021.02.28.433286; this version posted June 19,2021 . The copyright holder for this preprint (which was not certified by peer review) is the author/funder, who has granted bioRxiv a license to display the preprint in perpetuity. It is made available under aCC-BY-NC-ND 4.0 International license.

711 learning task carried out by instructor-learner dyads with their brain activity

712 simultaneously measured using fNIRS. As feedback information unfolded over time,

713 instructor-learner neural synchronization was observed in frontoparietal regions,

714 especially when examples were provided, and predicted the transfer of conceptual

715 knowledge to novel contexts. Inter-brain dynamics may provide a novel lens for people

716 to understand more about how elaborated feedback and learner-instructor interactions

717 shape learning and transfer, thence unmasks the neurocognitive basis of feedback

718 provided in a social context and contributes to pedagogical efficacy. 
bioRxiv preprint doi: https://doi org/10.1101/2021.02 28.433286; this version posted June 19,2021 . The copyright holder for this preprint (which was not certified by peer review) is the author/funder, who has granted bioRxiv a license to display the preprint in perpetuity. It is made available under aCC-BY-NC-ND 4.0 International license.

\section{References}

721 Allen, S. W., \& Brooks, L. R. (1991). Specializing the operation of an explicit rule. Journal of experimental psychology: General, 120(1), 3-19.

Andre, T., \& Thieman, A. (1988). Level of adjunct question, type of feedback, and learning concepts by reading. Contemporary Educational Psychology, 13(3), 296-307.

Arbel, Y., Goforth, K., \& Donchin, E. (2013). The good, the bad, or the useful? The examination of the relationship between the feedback-related negativity (FRN) and long-term learning outcomes. Journal of Cognitive Neuroscience, 25(8), 1249-1260.

Baker, J. M., Liu, N., Cui, X., Vrticka, P., Saggar, M., Hosseini, S. H., \& Reiss, A. L. (2016). Sex differences in neural and behavioral signatures of cooperation revealed by fNIRS hyperscanning. Scientific reports, 6, 26492.

Bangert-Drowns, R. L., Kulik, C. L. C., Kulik, J. A., \& Morgan, M. (1991). The instructional effect of feedback in test-like events. Review of educational research, 61(2), 213-238.

Benjamini, Y., \& Hochberg, Y. (1995). Controlling the false discovery rate: a practical and powerful approach to multiple testing. Journal of the Royal statistical society: series B (Methodological), 57(1), 289-300.

Bevilacqua, D., Davidesco, I., Wan, L., Chaloner, K., Rowland, J., Ding, M., ... \& Dikker, S. (2019). Brain-to-brain synchrony and learning outcomes vary by student-teacher dynamics: Evidence from a real-world classroom electroencephalography study. Journal of cognitive neuroscience, 31(3), $401-411$.

Bilek, E., Stößel, G., Schäfer, A., Clement, L., Ruf, M., Robnik, L., ... \& Meyer-Lindenberg, A. (2017). State-dependent cross-brain information flow in borderline personality disorder. JAMA psychiatry, 74(9), 949-957.

Boas, D. A., Elwell, C. E., Ferrari, M., \& Taga, G. (2014). Twenty years of functional near-infrared spectroscopy: introduction for the special issue. NeuroImage, $85,1-5$.

Bransford, J. D., Brown, A. L., \& Cocking, R. R. (1999). How people learn: Brain, mind, experience, and school. Washington, DC: National Academy Press.

Butler, A. C., Godbole, N., \& Marsh, E. J. (2013). Explanation feedback is better than correct answer feedback for promoting transfer of learning. Journal of Educational Psychology, 105(2), 290-298. 
bioRxiv preprint doi: https://doi.org/10.1101/2021.02 28.433286; this version posted June 19,2021 . The copyright holder for this preprint (which was not certified by peer review) is the author/funder, who has granted bioRxiv a license to display the preprint in perpetuity. It is made available under aCC-BY-NC-ND 4.0 International license.

\section{ELABORATED FEEDABCK AND TRANSFER}

increases retention of low-confidence correct responses. Journal of Experimental Psychology: Learning, Memory, and Cognition, 34(4), 918-928.

Button, S. B., Mathieu, J. E., \& Zajac, D. M. (1996). Goal orientation in organizational research: A conceptual and empirical foundation. Organizational behavior and human decision processes, 67(1), 26-48.

Cavanagh, J. F., Figueroa, C. M., Cohen, M. X., \& Frank, M. J. (2012). Frontal theta reflects uncertainty and unexpectedness during exploration and exploitation. Cerebral cortex, 22(11), 2575-2586.

Chang, C., \& Glover, G. H. (2010). Time-frequency dynamics of resting-state brain connectivity measured with fMRI. Neuroimage, 50(1), 81-98.

Cheng, X., Li, X., \& Hu, Y. (2015). Synchronous brain activity during cooperative exchange depends on gender of partner: A fNIRS-based hyperscanning study. Human brain mapping, 36(6), 2039-2048.

Cohen, V. B. (1985). A reexamination of feedback in computer-based instruction: Implications for instructional design. Educational Technology, 25(1), 33-37.

Cooper, R., Selb, J., Gagnon, L., Phillip, D., Schytz, H. W., Iversen, H. K., ... \& Boas, D. A. (2012). A systematic comparison of motion artifact correction techniques for functional near-infrared spectroscopy. Frontiers in neuroscience, 6, 147.

Cope, M., \& Delpy, D. T. (1988). System for long-term measurement of cerebral blood and tissue oxygenation on newborn infants by near infra-red transillumination. Medical and Biological Engineering and Computing, 26(3), 289-294.

Crone, E. A., Zanolie, K., Van Leijenhorst, L., Westenberg, P. M., \& Rombouts, S. A. (2008). Neural mechanisms supporting flexible performance adjustment during development. Cognitive, Affective, \& Behavioral Neuroscience, 8(2), 165-177.

Cui, X., Bryant, D. M., \& Reiss, A. L. (2012). NIRS-based hyperscanning reveals increased interpersonal coherence in superior frontal cortex during cooperation. Neuroimage, 59(3), 2430-2437.

Cui, X., Stetson, C., Montague, P. R., \& Eagleman, D. M. (2009). Ready... go: amplitude of the fMRI signal encodes expectation of cue arrival time. PLoS Biol, 7(8), e1000167.

Dai, B., Chen, C., Long, Y., Zheng, L., Zhao, H., Bai, X., ... \& Ding, G. (2018). Neural mechanisms for selectively tuning in to the target speaker in a naturalistic noisy situation. Nature communications, 9(1), 1-12.

DeVault, D., Sagae, K., \& Traum, D. (2011). Incremental interpretation and prediction of utterance 
bioRxiv preprint doi: https://doi org/101101/2021.02.28 433286; this version posted June 19 2021. The copyright holder for this preprint (which was not certified by peer review) is the author/funder, who has granted bioRxiv a license to display the preprint in perpetuity. It is made available under aCC-BY-NC-ND 4.0 International license.

meaning for interactive dialogue. Dialogue \& Discourse, 2(1), 143-170.

Dikker, S., Wan, L., Davidesco, I., Kaggen, L., Oostrik, M., McClintock, J., ... \& Poeppel, D. (2017). Brain-to-brain synchrony tracks real-world dynamic group interactions in the classroom. Current Biology, 27(9), 1375-1380.

Dion, J. S., \& Restrepo, G. (2016). A systematic review of the literature linking neural correlates of feedback processing to learning. Zeitschrift für Psychologie, 224(4), 247-256.

Faraggi, D., \& Reiser, B. (2002). Estimation of the area under the ROC curve. Statistics in medicine, 21(20), 3093-3106.

Finn, B., Thomas, R., \& Rawson, K. A. (2018). Learning more from feedback: Elaborating feedback with examples enhances concept learning. Learning and Instruction, 54, 104-113.

Fyfe, E. R., Rittle-Johnson, B., \& DeCaro, M. S. (2012). The effects of feedback during exploratory mathematics problem solving: Prior knowledge matters. Journal of Educational Psychology, 104, 1094-1108.

Gagne, R. M. (1970). The conditions of learning (2nd ed.). New York: Holt, Rinehart \& Winston.

Gilboa, A., \& Marlatte, H. (2017). Neurobiology of schemas and schema-mediated memory. Trends in cognitive sciences, 21(8), 618-631.

Graesser, A. C., Millis, K. K., \& Zwaan, R. A. (1997). Discourse comprehension. Annual Review of Psychology, 48, 163-189.

Grinsted, A., Moore, J. C., \& Jevrejeva, S. (2004). Application of the cross wavelet transform and wavelet coherence to geophysical time series. Nonlinear Processes in Geophysics, 11, 561-566.

Hamilton, A. F. D. C. (2021). Hyperscanning: beyond the hype. Neuron, 109(3), 404-407. factors and ergonomics society annual meeting (Vol. 50, No. 9, pp. 904-908). Sage CA: Los Angeles, CA: Sage publications.

Hasson, U., Chen, J., \& Honey, C. J. (2015). Hierarchical process memory: memory as an integral component of information processing. Trends in cognitive sciences, 19(6), 304-313. a mechanism for creating and sharing a social world. Trends in cognitive sciences, 16(2), 114-121. 
bioRxiv preprint doi: https://doi.org/10.1101/2021.02 28.433286; this version posted June 19,2021 . The copyright holder for this preprint (which was not certified by peer review) is the author/funder, who has granted bioRxiv a license to display the preprint in perpetuity. It is made available under aCC-BY-NC-ND 4.0 International license.

Henry, J. C. (2006). Electroencephalography: Basic principles, clinical applications, and related fields. Neurology, 67(11), 2092-2092.

Holper, L., Goldin, A. P., Shalóm, D. E., Battro, A. M., Wolf, M., \& Sigman, M. (2013). The teaching and the learning brain: A cortical hemodynamic marker of teacher-student interactions in the Socratic dialog. International Journal of Educational Research, 59, 1-10.

Hoshi, Y. (2007). Functional near-infrared spectroscopy: current status and future prospects. Journal of biomedical optics, 12(6), 062106.

Hou, Y. (2018). Social Psychology. Peking University Press: Beijing.

Hou, Y., Song, B., Hu, Y., Pan, Y., \& Hu, Y. (2020). The averaged inter-brain coherence between the audience and a violinist predicts the popularity of violin performance. NeuroImage, 211, 116655.

Hu, Y., Hu, Y., Li, X., Pan, Y., \& Cheng, X. (2017). Brain-to-brain synchronization across two persons predicts mutual prosociality. Social Cognitive and Affective Neuroscience, 12(12), 1835-1844.

Huppert, T. J., Diamond, S. G., Franceschini, M. A., \& Boas, D. A. (2009). HomER: a review of timeseries analysis methods for near-infrared spectroscopy of the brain. Applied optics, 48(10), D280D298. comparison of BOLD, ASL, and NIRS hemodynamic responses to motor stimuli in adult humans. Neuroimage, 29(2), 368-382.

Jacoby, L. L., Shimizu, Y., Daniels, K. A., \& Rhodes, M. G. (2005). Modes of cognitive control in recognition and source memory: Depth of retrieval. Psychonomic bulletin \& review, 12(5), 852857.

Jiang, J., Dai, B., Peng, D., Zhu, C., Liu, L., \& Lu, C. (2012). Neural synchronization during face-to-face communication. Journal of Neuroscience, 32(45), 16064-16069. interpersonal neural synchronization. Proceedings of the National Academy of Sciences, 112(14),

Jiang, J., Zheng, L., \& Lu, C. (2021). A hierarchical model for interpersonal verbal communication. Social Cognitive and Affective Neuroscience, 16(1-2), 246-255.

Kanske, P., Böckler, A., Trautwein, F. M., \& Singer, T. (2015). Dissecting the social brain: Introducing the EmpaToM to reveal distinct neural networks and brain-behavior relations for empathy and 
bioRxiv preprint doi: https://doi org/10.1101/2021.02.28 433286; this version posted June 19 2021. The copyright holder for this preprint (which was not certified by peer review) is the author/funder, who has granted bioRxiv a license to display the preprint in perpetuity. It is made available under aCC-BY-NC-ND 4.0 International license.

Theory of Mind. Neuroimage, 122, 6-19.

Kerns, J. G., Cohen, J. D., MacDonald, A. W., Cho, R. Y., Stenger, V. A., \& Carter, C. S. (2004). Anterior cingulate conflict monitoring and adjustments in control. Science, 303(5660), 1023-1026.

Kintsch, W. (1998). Comprehension: A paradigm for cognition. Cambridge, UK: Cambridge University Press.

Krause, U. M., Stark, R., \& Mandl, H. (2009). The effects of cooperative learning and feedback on e-learning in statistics. Learning and instruction, 19(2), 158-170.

Kulhavy, R. W., \& Stock, W. A. (1989). Feedback in written instruction: The place of response certitude. Educational psychology review, 1(4), 279-308.

Kulhavy, R. W., White, M. T., Topp, B. W., Chan, A. L., \& Adams, J. (1985). Feedback complexity and corrective efficiency. Contemporary educational psychology, 10(3), 285-291.

Kulhavy, R. W. (1977). Feedback in written instruction. Review of educational research, 47(2), 211-232.

Kingsbury, L., \& Hong, W. (2020). A Multi-Brain Framework for Social Interaction. Trends in Neurosciences.

Kosinski, M., Stillwell, D., \& Graepel, T. (2013). Private traits and attributes are predictable from digital records of human behavior. Proceedings of the national academy of sciences, 110(15), 5802-5805.

Leong, V., Byrne, E., Clackson, K., Harte, N., Lam, S., \& Wass, S. (2017). Speaker gaze changes information coupling between infant and adult brains. Proceedings of the National Academy of Sciences of the USA, 114(50), 13290-13295.

Leong, V., \& Schilbach, L. (2019). The promise of two-person neuroscience for developmental psychiatry: Using interaction-based sociometrics to identify disorders of social interaction. British Journal of Psychiatry, 215(5), 636-638.

Lepper, M. R., \& Chabay, R. W. (1985). Intrinsic motivation and instruction: Conflicting views on the role of motivational processes in computer-based education. Educational Psychologist, 20(4), 217230.

Liu, Y., Piazza, E. A., Simony, E., Shewokis, P. A., Onaral, B., Hasson, U., \& Ayaz, H. (2017). Measuring speaker-listener neural coupling with functional near infrared spectroscopy. Scientific reports, $7(1), 1-13$.

Liu, J., Zhang, R., Geng, B., Zhang, T., Yuan, D., Otani, S., \& Li, X. (2019). Interplay between prior knowledge and communication mode on teaching effectiveness: interpersonal neural 
bioRxiv preprint doi: https://doi org/10.1101/2021.02 28.433286; this version posted June 19,2021 . The copyright holder for this preprint (which was not certified by peer review) is the author/funder, who has granted bioRxiv a license to display the preprint in perpetuity. It is made available under aCC-BY-NC-ND 4.0 International license.

synchronization as a neural marker. Neuroimage, 193, 93-102.

871 Luft, C. D. B. (2014). Learning from feedback: the neural mechanisms of feedback processing facilitating

872 better performance. Behavioural brain research, 261, 356-368.

873 Luft, C. D. B., Nolte, G., \& Bhattacharya, J. (2013). High-learners present larger mid-frontal theta power 874 and connectivity in response to incorrect performance feedback. Journal of Neuroscience, 33(5), 2029-2038.

Mandernach, B. J. (2005). Relative effectiveness of computer-based and human feedback for enhancing student learning. The Journal of Educators Online, 2(1), 1-17.

878 Mars, R. B., Coles, M. G., Grol, M. J., Holroyd, C. B., Nieuwenhuis, S., Hulstijn, W., \& Toni, I. (2005). Neural dynamics of error processing in medial frontal cortex. Neuroimage, 28(4), 1007-1013.

Maris, E., \& Oostenveld, R. (2007). Nonparametric statistical testing of EEG-and MEG-data. Journal of neuroscience methods, 164(1), 177-190.

McCormick, E. M., \& Telzer, E. H. (2018). Not doomed to repeat: Enhanced medial prefrontal cortex tracking of errors promotes adaptive behavior during adolescence. Journal of cognitive neuroscience, 30(3), 281-289.

Melcher, D. (2006). Accumulation and persistence of memory for natural scenes. Journal of vision, 6(1), 2.

Meshulam, M., Hasenfratz, L., Hillman, H., Liu, Y. F., Nguyen, M., Norman, K. A., \& Hasson, U. (2021). Neural alignment predicts learning outcomes in students taking an introduction to computer science course. Nature communications, 12(1), 1-14.

Michel, M., \& Morales, J. (2020). Minority reports: Consciousness and the prefrontal cortex. Mind \& Language, 35(4), 493-513.

Molavi, B., \& Dumont, G. A. (2012). Wavelet-based motion artifact removal for functional near-infrared spectroscopy. Physiological measurement, 33(2), 259-270.

Morris, C. D., Bransford, J. D., \& Franks, J. J. (1977). Levels of processing versus transfer appropriate processing. Journal of verbal learning and verbal behavior, 16(5), 519-533. and technology, 2, 745-783.

Murphy, G. (2004). The big book of concepts. MIT press.

Nguyen, M., Chang, A., Micciche, E., Meshulam, M., Nastase, S. A., \& Hasson, U. (2020). Teacher- 
bioRxiv preprint doi: https://doi org/10.1101/2021.02.28 433286; this version posted June 19,2021 . The copyright holder for this preprint (which was not certified by peer review) is the author/funder, who has granted bioRxiv a license to display the preprint in perpetuity. It is made available under aCC-BY-NC-ND 4.0 International license.

900

901

902

903

904

905

906

907

908

909

910

911

912

913

914

915

916

917

918

919

920

921

922

923

924

925

926

927

928

929

student neural coupling during teaching and learning. bioRxiv.

Novembre, G., \& Iannetti, G. D. (2021). Hyperscanning Alone Cannot Prove Causality. Multibrain Stimulation Can. Trends in Cognitive Sciences. 25(2), 96-99.

Nozawa, T., Sasaki, Y., Sakaki, K., Yokoyama, R., \& Kawashima, R. (2016). Interpersonal frontopolar neural synchronization in group communication: an exploration toward fNIRS hyperscanning of natural interactions. Neuroimage, 133, 484-497.

Ojemann, G., Ojemann, J., Lettich, E., \& Berger, M. (2008). Cortical language localization in left, dominant hemisphere: An electrical stimulation mapping investigation in 117 patients. Journal of neurosurgery, 108(2), 411-421.

Pan, Y., Cheng, X., Zhang, Z., Li, X., \& Hu, Y. (2017). Cooperation in lovers: An fNIRS-based hyperscanning study. Human brain mapping, 38(2), 831-841.

Pan, Y., Dikker, S., Goldstein, P., Zhu, Y., Yang, C., \& Hu, Y. (2020). Instructor-learner brain coupling discriminates between instructional approaches and predicts learning. NeuroImage, 116657.

Pan, Y., Novembre, G., \& Olsson, A. (2021a). The interpersonal neuroscience of social learning. PsyArxiv.

Pan, Y., Novembre, G., Song, B., Li, X., \& Hu, Y. (2018). Interpersonal synchronization of inferior frontal cortices tracks social interactive learning of a song. Neuroimage, 183, 280-290.

Pan, Y., Novembre, G., Song, B., Zhu, Y., \& Hu, Y. (2021b). Dual brain stimulation enhances interpersonal learning through spontaneous movement synchrony. Social Cognitive and Affective Neuroscience, 16(1-2), 210-221.

Pashler, H., Cepeda, N. J., Wixted, J. T., \& Rohrer, D. (2005). When does feedback facilitate learning of words?. Journal of Experimental Psychology: Learning, Memory, and Cognition, 31(1), 3-8.

Pastorino, E. E., \& Doyle-Portillo, S. M. (2008). What Is Psychology? Essentials. Wadsworth.

Piazza, E. A., Hasenfratz, L., Hasson, U., \& Lew-Williams, C. (2020). Infant and Adult Brains Are Coupled to the Dynamics of Natural Communication. Psychological Science, 31(1), 6-17.

Piazza, E. A., Cohen, A., Trach, J., \& Lew-Williams, C. (2021). Neural synchrony predicts children's learning of novel words. Cognition, 214, 104752.

Pickering, M. J., \& Garrod, S. (2013). An integrated theory of language production and comprehension. Behavioral and brain sciences, 36(04), 329-347.

Pinti, P., Tachtsidis, I., Hamilton, A., Hirsch, J., Aichelburg, C., Gilbert, S., \& Burgess, P. W. (2020). The present and future use of functional near-infrared spectroscopy (fNIRS) for cognitive 
bioRxiv preprint doi: https://doi.org/10.1101/2021.02 28.433286; this version posted June 19,2021 . The copyright holder for this preprint (which was not certified by peer review) is the author/funder, who has granted bioRxiv a license to display the preprint in perpetuity. It is made available under aCC-BY-NC-ND 4.0 International license.

neuroscience. Annals of the New York Academy of Sciences, 1464(1), 5.

Rawson, K. A., Thomas, R. C., \& Jacoby, L. L. (2015). The power of examples: illustrative examples enhance conceptual learning of declarative concepts. Educational Psychology Review, 27(3), 483504.

Redcay, E., \& Schilbach, L. (2019). Using second-person neuroscience to elucidate the mechanisms of social interaction. Nature Reviews Neuroscience, 20(8), 495-505.

Reindl, V., Gerloff, C., Scharke, W., \& Konrad, K. (2018). Brain-to-brain synchrony in parent-child dyads and the relationship with emotion regulation revealed by fNIRS-based hyperscanning. NeuroImage, 178, 493-502.

Peters, S., Braams, B. R., Raijmakers, M. E., Koolschijn, P. C. M., \& Crone, E. A. (2014). The neural coding of feedback learning across child and adolescent development. Journal of Cognitive Neuroscience, 26(8), 1705-1720.

Peters, S., Van Duijvenvoorde, A. C., Koolschijn, P. C. M., \& Crone, E. A. (2016). Longitudinal development of frontoparietal activity during feedback learning: Contributions of age, performance, working memory and cortical thickness. Developmental Cognitive Neuroscience, 19, 211-222.

Peters, S., Van der Meulen, M., Zanolie, K., \& Crone, E. A. (2017). Predicting reading and mathematics from neural activity for feedback learning. Developmental psychology, 53(1), 149-159.

Phye, G. D., \& Sanders, C. E. (1994). Advice and feedback: Elements of practice for problem solving. Contemporary Educational Psychology, 19(3), 286-301.

Pinti, P., Tachtsidis, I., Hamilton, A., Hirsch, J., Aichelburg, C., Gilbert, S., \& Burgess, P. W. (2018). The present and future use of functional near - infrared spectroscopy (fNIRS) for cognitive neuroscience. Annals of the New York Academy of Sciences, 1-25.

Pintrich, P. R., \& De Groot, E. V. (1990). Motivational and self-regulated learning components of classroom academic performance. Journal of educational psychology, 82(1), 33-40.

Rushworth, M. F., Buckley, M. J., Behrens, T. E., Walton, M. E., \& Bannerman, D. M. (2007). Functional organization of the medial frontal cortex. Current opinion in neurobiology, 17(2), 220-227. 
bioRxiv preprint doi: https://doi.org/10.1101/2021.02 28.433286; this version posted June 19,2021 . The copyright holder for this preprint (which was not certified by peer review) is the author/funder, who has granted bioRxiv a license to display the preprint in perpetuity. It is made available under aCC-BY-NC-ND 4.0 International license.

960

961

962

963

964

965

966

967

968

969

970

971

972

973

974

975

976

977

978

979

980

981

982

983

984

985

986

987

988

989

psychology, 33(5), 464-481.

Schilbach, L., Timmermans, B., Reddy, V., Costall, A., Bente, G., Schlicht, T., \& Vogeley, K. (2013). Toward a second-person neuroscience. Behavioral and brain sciences, 36(4), 393-414.

Schurz, M., Radua, J., Aichhorn, M., Richlan, F., \& Perner, J. (2014). Fractionating theory of mind: a meta-analysis of functional brain imaging studies. Neuroscience \& Biobehavioral Reviews, 42, 934.

Shute, V. J. (2008). Focus on formative feedback. Review of educational research, 78(1), 153-189.

Singh, A. K., Okamoto, M., Dan, H., Jurcak, V., \& Dan, I. (2005). Spatial registration of multichannel multi-subject fNIRS data to MNI space without MRI. Neuroimage, 27(4), 842-851.

Stephens, G. J., Silbert, L. J., \& Hasson, U. (2010). Speaker-listener neural coupling underlies successful communication. Proceedings of the National Academy of Sciences, 107(32), 14425-14430.

Tang, H., Zhang, S., Jin, T., Wu, H., Su, S., \& Liu, C. (2019). Brain activation and adaptation of deception processing during dyadic face-to-face interaction. Cortex, 120, 326-339.

Tatler, B. W., Gilchrist, I. D., \& Rusted, J. (2003). The time course of abstract visual representation. Perception, 32(5), 579-592.

Teplan, M. (2002). Fundamentals of EEG measurement. Measurement science review, 2(2), 1-11.

Theiler, J., Galdrikian, B., Longtin, A., Eubank, S., \& Farmer, J. D. (1991). Testing for nonlinearity in time series: the method of surrogate data (No. LA-UR-91-3343; CONF-9108181-1). Los Alamos National Lab., NM (United States).

Thomas, R. C., \& McDaniel, M. A. (2013). Testing and feedback effects on front-end control over later retrieval. Journal of Experimental Psychology: Learning, Memory, and Cognition, 39(2), $437-450$.

Torrence, C., \& Compo, G. P. (1998). A practical guide to wavelet analysis. Bulletin of the American Meteorological society, 79(1), 61-78.

Tulving, E., \& Thomson, D. M. (1973). Encoding specificity and retrieval processes in episodic memory. Psychological review, 80(5), 352-373.

Tsuzuki, D., Jurcak, V., Singh, A. K., Okamoto, M., Watanabe, E., \& Dan, I. (2007). Virtual spatial registration of stand-alone fNIRS data to MNI space. Neuroimage, 34(4), 1506-1518.

van der Helden, J., Boksem, M. A., \& Blom, J. H. (2010). The importance of failure: feedback-related negativity predicts motor learning efficiency. Cerebral Cortex, 20(7), 1596-1603. 
bioRxiv preprint doi: https://doi.org/10.1101/2021.02 28.433286; this version posted June 19,2021 . The copyright holder for this preprint (which was not certified by peer review) is the author/funder, who has granted bioRxiv a license to display the preprint in perpetuity. It is made available under aCC-BY-NC-ND 4.0 International license.

Van Duijvenvoorde, A. C., Zanolie, K., Rombouts, S. A., Raijmakers, M. E., \& Crone, E. A. (2008). learning across development. Journal of Neuroscience, 28(38), 9495-9503.

Vigneau, M., Beaucousin, V., Herve, P. Y., Duffau, H., Crivello, F., Houde, O., ... \& Tzourio-Mazoyer, N. (2006). Meta-analyzing left hemisphere language areas: phonology, semantics, and sentence processing. Neuroimage, 30(4), 1414-1432.

Wass, S.V., Whitehorn, M., Marriot Haresign, I., Phillips, E., \& Leong, V. (2020). Interpersonal neural synchrony and responsivity during early learning interactions. Trends in Cognitive Sciences, 24(4), $329-342$.

Wheatley, T., Boncz, A., Toni, I., \& Stolk, A. (2019). Beyond the Isolated Brain: The Promise and Challenge of Interacting Minds. Neuron, 103(2), 186-188.

Yang, J., Zhang, H., Ni, J., De Dreu, C. K., \& Ma, Y. (2020). Within-group synchronization in the prefrontal cortex associates with intergroup conflict. Nature Neuroscience, 23(6), 754-760.

Zanolie, K., Van Leijenhorst, L., Rombouts, S. A. R. B., \& Crone, E. A. (2008). Separable neural mechanisms contribute to feedback processing in a rule-learning task. Neuropsychologia, 46(1), $117-126$.

Zimbardo, P. G., Johnson, R. L. \& McCann, V. (2012). Psychology: Core Concepts (Seventh Edition). Upper Saddle River, NJ: Pearson. outcome through neural prediction of the students' knowledge state. Human brain mapping, 39(7), 3046-3057. 
bioRxiv preprint doi: https://doi.org/10.1101/2021.02 28.433286; this version posted June 19, 2021. The copyright holder for this preprint (which was not certified by peer review) is the author/funder, who has granted bioRxiv a license to display the preprint in perpetuity. It is made available under aCC-BY-NC-ND 4.0 International license.

Figure 1

1013 Experimental protocol, channel locations and WTC analysis

a

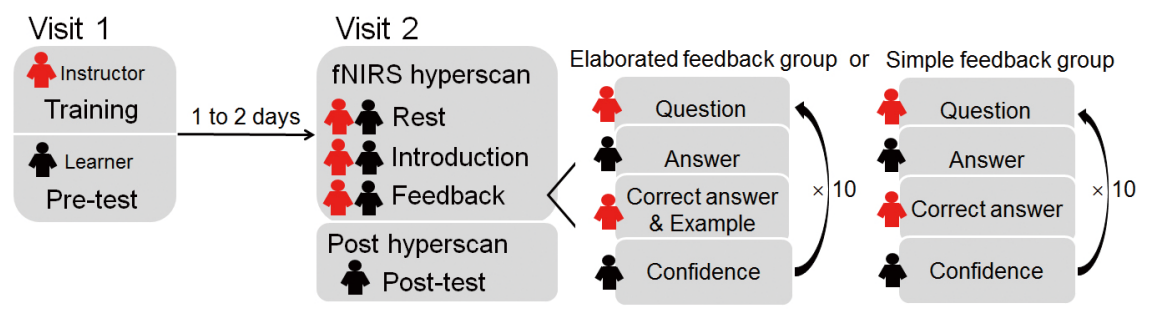

b

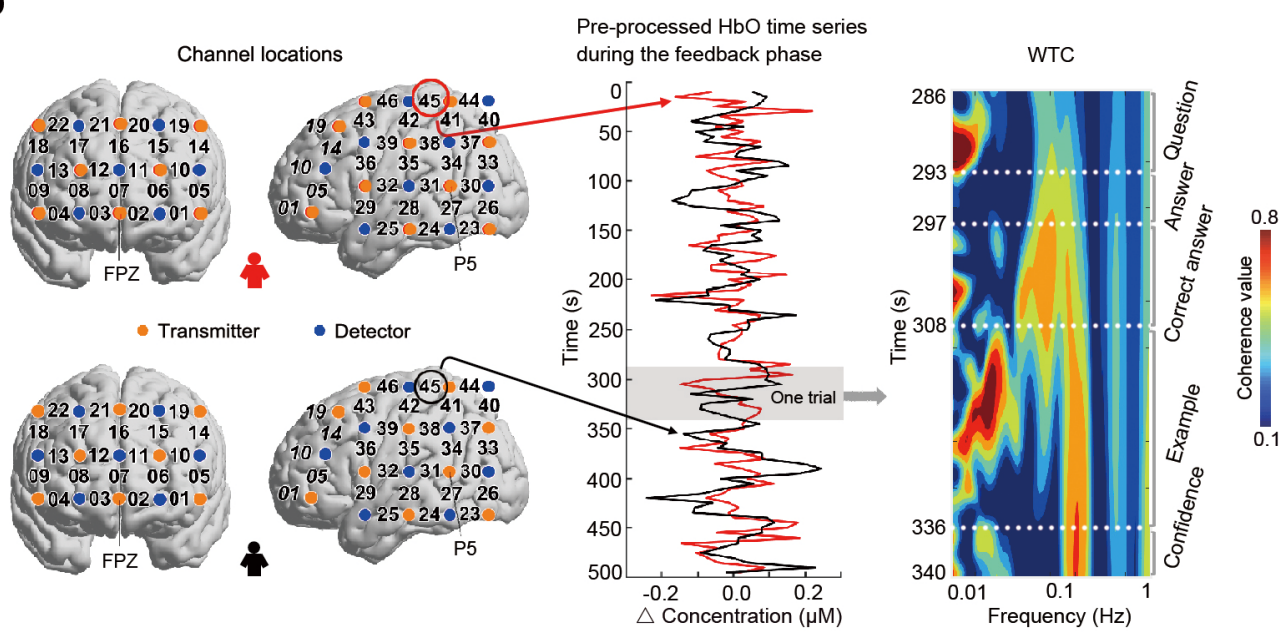

Note. (a) Schematic of the experimental protocol. During the first visit, instructors underwent

a standardized training on the instructional procedure and content and leaners completed a pre-

learning test. During the second visit, instructor-learner dyads first rested. Then instructors

introduced 10 concepts, during which the term and definition were orally presented twice. Next, measurement channels and illustration of WTC analysis. On the left panel, two optode probes

1024 were placed over instructors' and learners' frontal and left temporoparietal areas, respectively.

1025 Measurement channels were located between one transmitter (orange) and one adjacent detector 1026 (blue). Location references were placed at FPZ and P5 according to 10-10 international system. 
bioRxiv preprint doi: https://doi.org/10.1101/2021.02.28.433286; this version posted June 19, 2021. The copyright holder for this preprint (which was not certified by peer review) is the author/funder, who has granted bioRxiv a license to display the preprint in perpetuity. It is made available under aCC-BY-NC-ND 4.0 International license.

\section{ELABORATED FEEDABCK AND TRANSFER}

series from $\mathrm{CH} 45$ during the feedback phase. On the right panel, the resulting WTC matrix

1029 (frequency $\times$ time) corresponding to one trial was visualized with color bar denoting the values.

$1030 \mathrm{HbO}$, oxy-hemoglobin; WTC, wavelet transform coherence. 
bioRxiv preprint doi: https://doi.org/10.1101/2021.02 28.433286; this version posted June 19,2021 . The copyright holder for this preprint (which was not certified by peer review) is the author/funder, who has granted bioRxiv a license to display the preprint in perpetuity. It is made available under aCC-BY-NC-ND 4.0 International license.

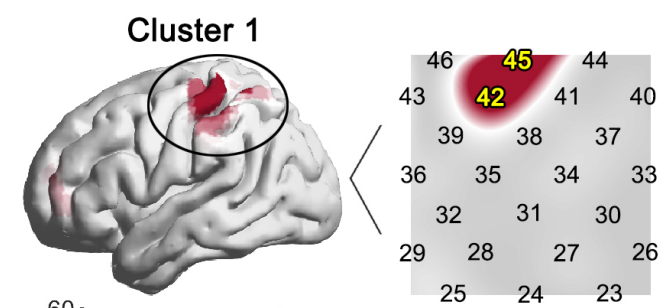

\section{Cluster 2}

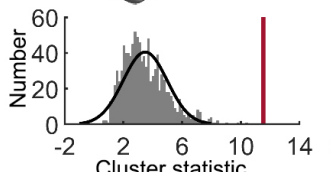

$25 \quad 24 \quad 23$
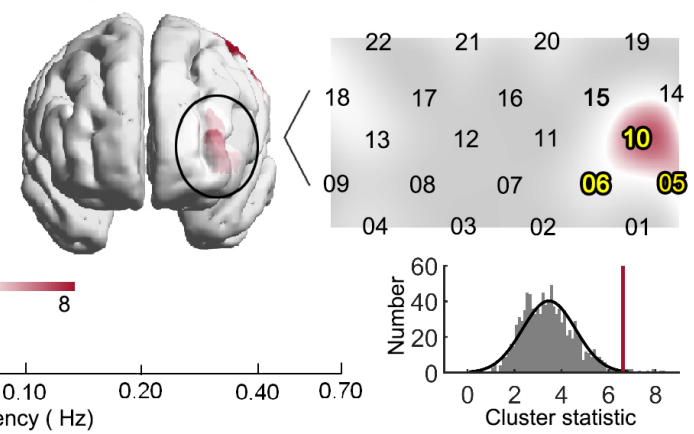

Note. Two significant clusters were identified. Cluster 1 was approximately located at the left

PoCG and left SPG within $0.017-0.025 \mathrm{~Hz}$ and Cluster 2 was approximately located at the left

SFG and left MFG within $0.017-0.024 \mathrm{~Hz}$ (with permutation tests, $p s<0.001$ ). Spatial locations

of the clusters are visualized at a representative frequency bin of $0.02 \mathrm{~Hz}$. Yellow numbers

1039 denote channels contained in the clusters. Red horizontal lines denote the frequency bands.

1040 Gray histograms depict the frequent distribution of null cluster statistics, while red vertical lines

1041 denote observed cluster statistics. 
bioRxiv preprint doi: https://doi.org/10.1101/2021.02 28.433286; this version posted June 19,2021 . The copyright holder for this preprint (which was not certified by peer review) is the author/funder, who has granted bioRxiv a license to display the preprint in perpetuity. It is made available under aCC-BY-NC-ND 4.0 International license.

\section{Figure 3}

Cluster 3

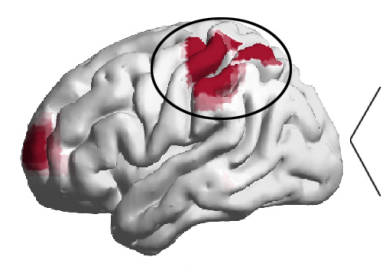

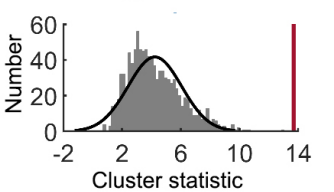

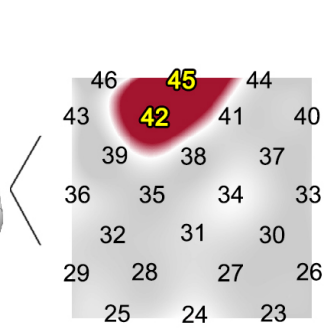

Cluster 4
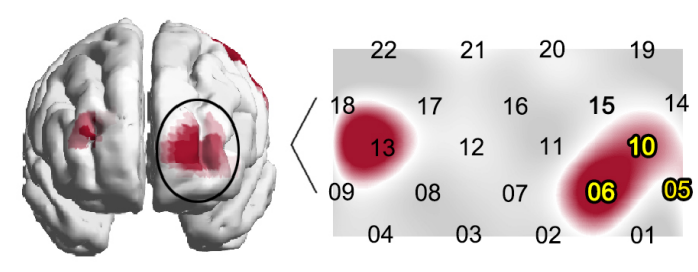

$25 \quad 24 \quad 23$

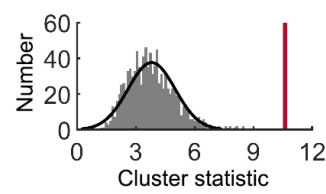

1046

Note. Two significant clusters were identified. Cluster 3 was approximately located at the left

PoCG and left SPG within $0.018-0.027 \mathrm{~Hz}$ and Cluster 2 was approximately located at the left

SFG and MFG within $0.015-0.023 \mathrm{~Hz}$ (with permutation tests, $p \mathrm{~s}<0.001$ ). Spatial locations of

1049 the clusters are visualized at a representative frequency bin of $0.02 \mathrm{~Hz}$. Yellow numbers denote

1050 channels contained in clusters. Red horizontal lines denote frequency bands. Gray histograms

1051 depict the frequent distribution of null cluster statistics, while red vertical lines denote observed cluster statistics. 
bioRxiv preprint doi: https://doi.org/10.1101/2021.02 28.433286; this version posted June 19,2021 . The copyright holder for this preprint (which was not certified by peer review) is the author/funder, who has granted bioRxiv a license to display the preprint in perpetuity. It is made available under aCC-BY-NC-ND 4.0 International license.

\section{Figure 4}

1055 Instructor-learner neural synchronization during example vs. correct answer.

1056

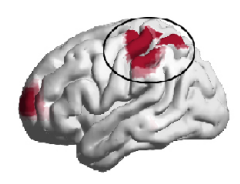

Cluster 3 a

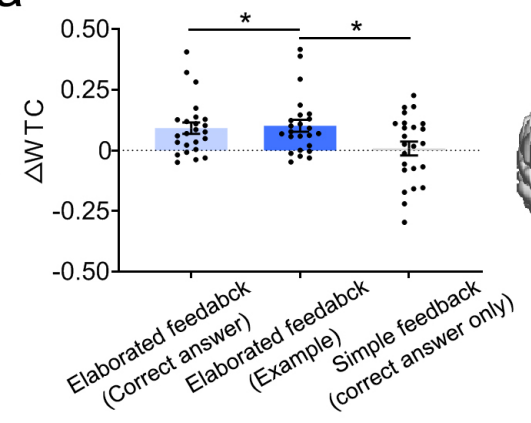

b

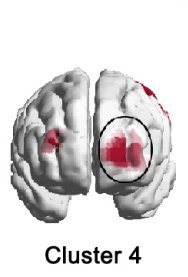

Cluster 4

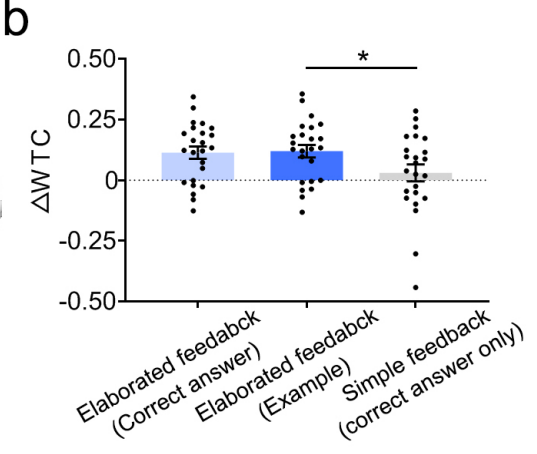

1057 Note. (a) On Cluster 3, example relative to correct answer part of elaborated feedback and 1058 simple feedback elicited significantly larger $\Delta$ WTC. (b) On Cluster 4, example relative to 1059 correct answer part of elaborated feedback elicited comparable $\triangle \mathrm{WTC}$, while example part of elaborated feedback relative to simple feedback elicited larger $\Delta$ WTC. ${ }^{*} p<0.05$. 
bioRxiv preprint doi: https://doi.org/10.1101/2021.02 28.433286; this version posted June 19,2021 . The copyright holder for this preprint (which was not certified by peer review) is the author/funder, who has granted bioRxiv a license to display the preprint in perpetuity. It is made available under aCC-BY-NC-ND 4.0 International license.

Figure 5

1063 Instructor-learner neural synchronization during the example part of elaborated feedback predicts transfer

a
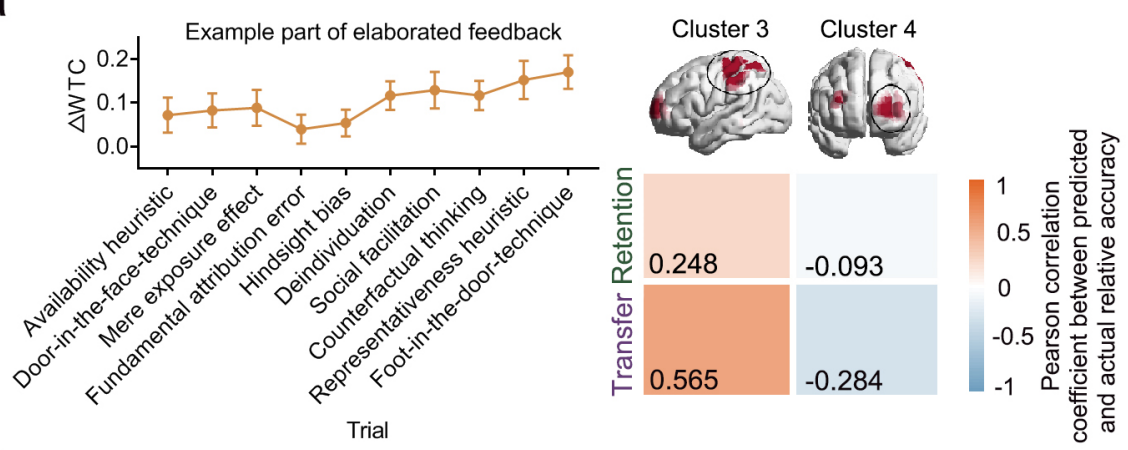

b

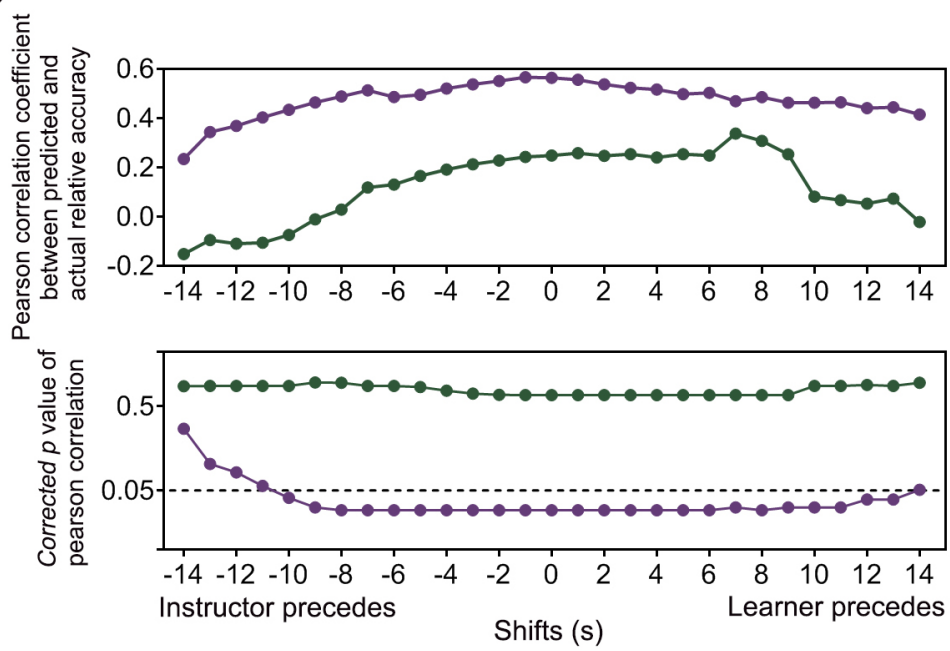

Sub-test:

- Transfer

- Retention

1065

Note. (a) Trial-by-trial $\Delta \mathrm{WTC}$ on Cluster 3 could successfully predict out-of-sample learners'

relative accuracy on the transfer measure but not on the retention measure. Warmer colors

indicate relatively higher prediction accuracy for a given cluster; cooler colors indicate

relatively lower prediction accuracy for a given cluster. (b). The prediction accuracy for Cluster

10703 on the transfer measure was significant when instructors' brain activity preceded learners' by

$1071 \quad 1-10 \mathrm{~s}$ and when learners' brain activity preceded instructors' by $1-13 \mathrm{~s}$ (-10-13, purple). 